\title{
PSYCHIATRIC MORBIDITY PRECEDING PSYCHOTIC- AND NON-PSYCHOTIC DEPRESSION
}

Søren Dinesen Østergaard (MD) ${ }^{1}$, Peter Thisted Dinesen $(\mathrm{PhD})^{2}$, Georgios Petrides (MD) ${ }^{3}$, Søren Skadhede ${ }^{1}$, Povl Munk-Jørgensen (MD, Prof) ${ }^{1}$, Jimmi Nielsen (MD, PhD) ${ }^{1}$

1 Unit For Psychiatric Research, Aalborg Psychiatric Hospital, Aarhus University Hospital, Aalborg, Denmark

Institute of Political Science and Public Management, University of Southern Denmark, Odense, Denmak

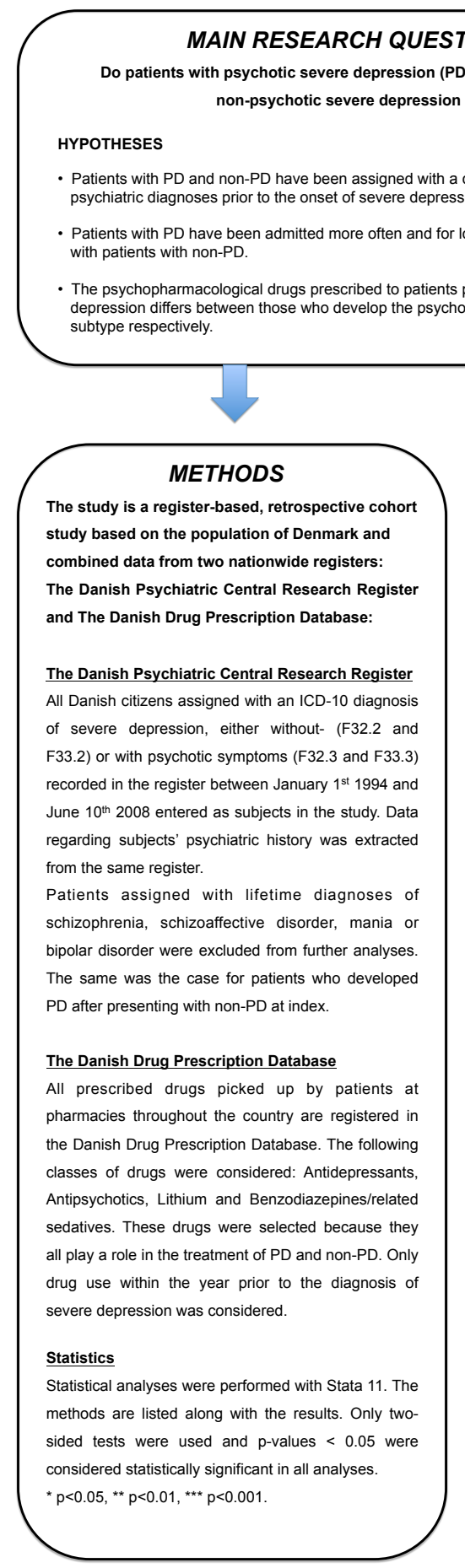

\section{RESULTS / CONCLUSIONS}

Patients with psychotic severe depression DO DIFFER from those with non-psychotic severe depression prior to the onset of the two disorders

- Patients with PD and non-PD ARE assigned with a different pattern of psychiatric diagnoses.

- Patients with PD ARE admitted more often AND for longer time compared to patients with non-PD.

- The psychopharmacological drugs prescribed to patients prior to the onset of severe depression DO DIFFER between those who develop the psychotic- and non-psychotic subtype respectively.

This study highlights several differences in the pre-diagnostic phase of PD and non-PD, offering further support to the hypothesis that the two subtypes are in fact different clinical syndromes. The Danish Psychiatric Central Research Register The Danish Psychiatric Central Research Register assigned with an $I C D-10$ diagnosis F33.2) or with psycholic recorded in the register between January $1^{\text {st }} 1994$ and ered as subjects in the study. Data The same was the case for patients who developed

\section{The Danish Drug Prescription Database}

Al prescribed drugs picked up by patients at classes of drugs were considered: Antidepressants, Antipsychotics, Lithium and Benzodiazepines/related all play a role in the treatment of $\mathrm{PD}$ and non-PD. Only drug use within the year prior to the diagnosis of Statistics considered statistically significant in all analyses.

${ }^{*} p<0.05,{ }^{* *} p<0.01,{ }^{* * *} p<0.001$
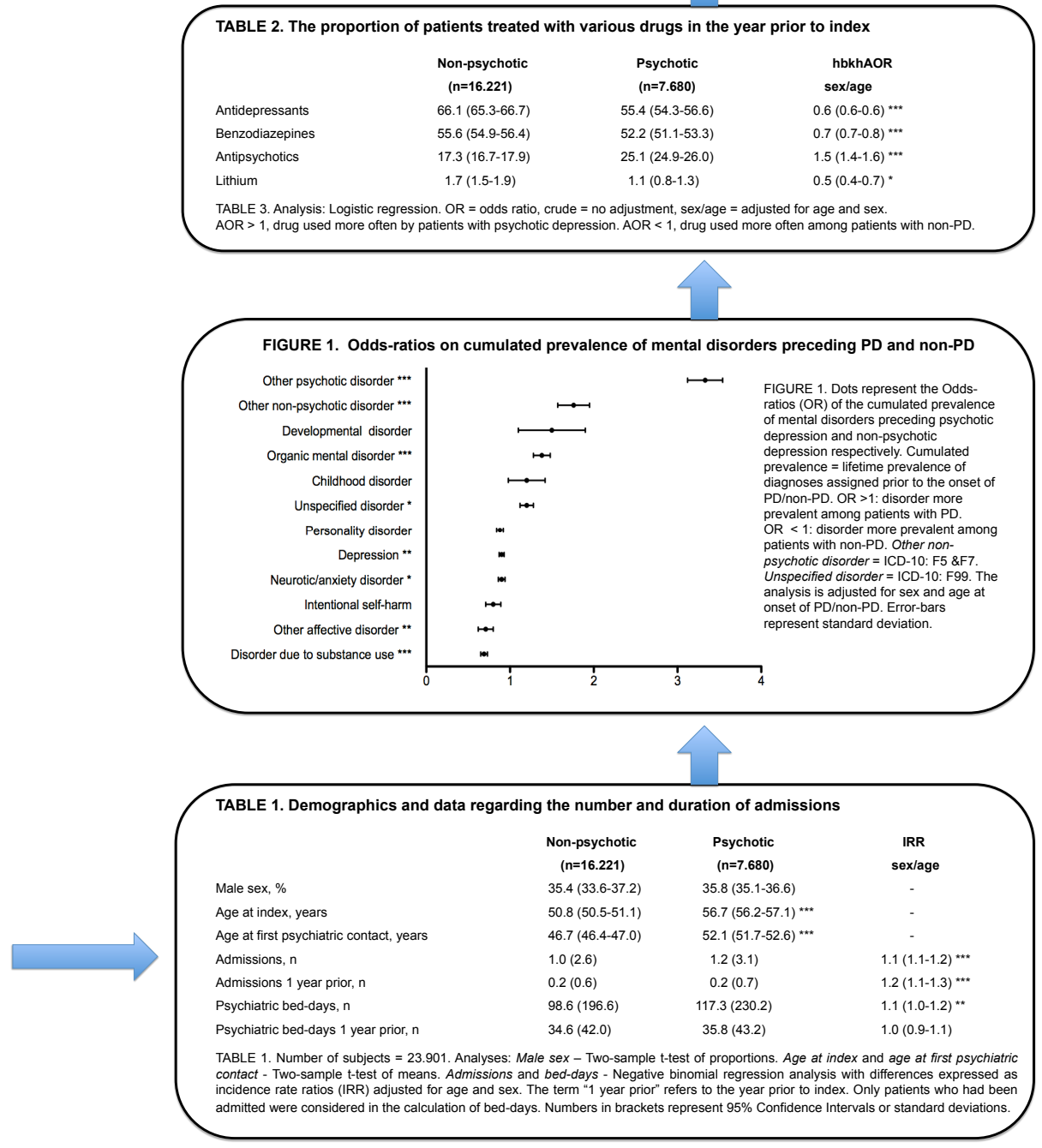

\section{KEY REFERENCES}

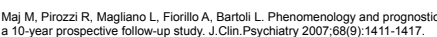

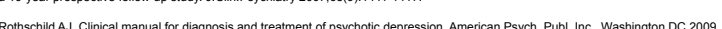

Glassman AH, Roose SP. Delusional depression. A distinct clinical entity? Arch Gen Psychiatry 1981; 38(4):4244-427.

Wijkstra J, Lijmer J, Balk F, Geddes J, Nolen WA. Pharmacological treatment for psychotic depression. Cochrane Database Syst Rev
2005; 4 (4):CD004044.

\section{DISCLOSURE}

Soren D. Østergaard has received minor honoraraia from Janssen-CCiag. P. Munk-Jorgensen has received non-conditional education grants and/or minor honoraraia from H. Lundbeck, AstraZeneca, Eli Lilly, Janssen-Cilag and Bristo-Myers Squibb. J. Nielsen has

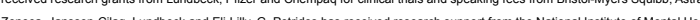
(NIMH), Novartis, Proteus, Corcept pharmaceuticals and Sinuvion. 